1965, describes the development of a pressurized water reactor suitable for ship propulsion-the so-called NERO project. Part of this, carried out in association with Euratom, has been completed (Pp. 15. The Hague: Reactor Centrum Nederland, 1965). Work at Petten is concerned with the reactor core, consisting of sintered uranium oxide fuel in zircalloy tubes. The fuel contains discrete particles of burnable neutron poison, for which $\mathrm{UB}_{4}$ and $\mathrm{Dy}_{2} \mathrm{O}_{3}$ are being considered. For testing, both the low-flux and the high-flux reactors have been used, and the effect of the introduction of poisoned fuel rods on the power distribution has been measured in the critical facility KRITO, using a two-zone core of $3 \cdot 1$ per cent and 3.8 per cent enrichment. The principal problem of the NERO design in the field of materials is the compatibility of the neutron poison particle with the fuel matrix, both during the fabrication of the fuel and during its life in the reactor.

The three reactors at Petten each play a part in the reactor development work and KRITO is used exclusively for that work. The 200-MW high-flux reactor is owned by Euratom as part of that organization's research establishment adjoining the RCN site but is operated by RCN. Two new loops and one new beamhole experiment have been installed. The experiment consists of a triple-axis spectrometer for the investigation of crystal lattice dynamics by the inelastic scattering of neutrons. Two other beamholes are in use for crystal structure studies by means of neutron diffraction. New information on the magnetic ordering in cobalt (II) oxide has been obtained. The $10-\mathrm{kW}$ low-flux reactor has been made more versatile by the addition of a trolley in the large sub-critical facility which occupies one side of the reactor.

\section{Rubbish in Estuaries}

A stUDy by the U.K.A.E.A. Isotope Research Division has illustrated the difficulties of selecting areas for the deposition of spoil and sewage. The initial studies, carried out in 1961 and 1964 in the Firth of Forth, show that the Oxcars deep region, which has been used as an area for the deposition of spoil dredged from Rosyth dockyard, is totally unsuitable for the purpose. Far from being swept out to sea, the silt moves upstream, and is ultimately deposited near the region from which it was originally dredged.

The technique used in the experiments utilized radioactive tracers. Glass was prepared to the same density and size distribution as the silt, and scandium-46 was incorporated to enable the movement of the silt to be detected by scintillation counter. A hopper containing 750 tons of silt from Rosyth dockyard was inoculated thoroughly with tracer material and deposited in the normal way in Oxcars deep, immediately after slack high water. Within 24 hours, traces of silt were detected above the Forth Bridge, while below Oxcars deep no trace could be found. This pattern was maintained throughout the nine weeks in which measurements were made, despite the fact that deposition of the spoil was made at a state of the tide least likely to carry material upstream. Deposition of spoil is normally carried out at all states of the tide.

A subsequent study in 1965 of an area superficially less attractive for the dumping of silt has given different results. Although this area is shallower than the Oxcars deep, it is in an ebb channel, and the silt is swept out into the estuary.

\section{Water in the United States}

THE drought that has persisted in the eastern United States for the past few years, causing New York City to be classified as a 'disaster area', has emphasized that water supply can be as much a problem in industrial areas as in the farming aroas of India and Africa. However, the problem for the United States should, with proper measures, be soluble. In a pamphlet for the United States Goological Survey, entitled Has the United States Enough Water?, A. M. Piper concludes that the United States can be assured of a sufficient water supply for essentia] needs within the near future if proper measures are taken soon. These include research before any decisions are made concerning management of water supplies; a realization that there is no one solution for all situations; compromise among potentially competitive uses; and large-scale investment for new water-management works.

Nearly all the fresh water comes from precipitation; rainfall in the United States varies from less than 4 in. per annum in the Pacific South-west to more than $85 \mathrm{in}$. in the Pacific North-west. This range of rainfall is complicated by an equally wide variation in potential 'cvapotranspiration'-water loss from open-water surface and vegetable transpiration-ranging from 18 in. per annum in the Rocky Mountains to 60 in. in Death Valley. Where evapotranspiration exceeds precipitation, the land is arid; where precipitation is greater, water overflows into streams.

Where local needs are greater than the minimum stream-flow (which varies with the seasons), the variations must be suppressed, usually by means of reservoirs. At present the cost of controlling the water in a stream basin continuously has not been acceptable. However, Mr. Piper thinks that the acceptable cost will increase substantially and that the limitation on water storage will be determined by engineering complexities, other potential land uses, or other objectives of stream management.

In $1960,270,000$ million gallons of water were withdrawn each day from rivers in the United States, while 68,000 million gallons were actually consumed, 86 per cent in irrigation. At tho present rate of increase, the total use of water will double in 25-30 years. When this increase is extrapolated forwards for each of sixteen regions in the United States, it appears that potential supply exceeds the likely commitment in only throe regions; in another seven regions water requirements will be realized if virtually complete regulation of the stream. flow is feasible. In the remaining nine regions it is expected that even with complete regulation of stream-flow, social and industrial developments will be handicapped.

\section{Lens Design at the N.B.S.}

The United States National Bureau of Standards has developed a procedure for the determination of lenses from design data alone, in response to a request from the Air Force Reconnaissance Laboratory at Wright Field and as an alternative to the expensive and time-consuming method of fabricating prototypes and then testing them. The system of optical design analysis is based on the use of spot diagrams, which are analogues of star image tests. In Monograph 93 of the National Bureau of Standards, O. R. Stavroudis and L. E. Sutton present an outline of the methods used to calculate, produce and interpret spot diagrams (United States Department of Commerce. Spot Diagrams for the Prediction of Lens Performance from Design Data. Pp. iii +96. Washington, D.C.: Government Printing Office, 1965. 75 cents).

A spot diagram is a plot of points representing tho intersections of rays from a given object point with a focal plane of a lens, and is calculated from the design specifications of the lens by the use of a fast digital computer. Within the framework of geometrical optics, the spot diagram can be interpreted in the same way as a star image produced by a real lens; it is the greatly magnified picture of the image of a point source as it would appear on the film plane of a camera using the lens. Hawkins and Linfoot in 1945 were the first to publish a report on spot diagrams when they described the performance of several designs of Schmidt cameras, and Herzberger, in 1947 , followed with a report on the method of calculating the spot diagrams. 